\title{
The pattern of expression of CD147/ neurothelin during human T-cell ontogeny as defined by the monoclonal antibody 8D6
}

\begin{abstract}
A. H. Kirsch, L. A. Diaz, Jr., B. Bonish, P. A. Antony, D. A. Fox. The pattern of expression of CD147/neurothelin during human T-cell ontogeny as defined by the monoclonal antibody $8 \mathrm{D} 6$.

Tissue Antigens 1997: 50: 147-152. @ Munksgaard, 1997

A novel monoclonal antibody termed 8D6 was generated against the human leukemic T-cell line Molt 13 and was found to recognize the neurothelin structure, recently termed CD147. UM8D6 precipitated a single band from HSB2 cells of molecular weight $35 \mathrm{kDa}$ nonreduced and $40 \mathrm{kDa}$ reduced. CD147 is broadly expressed on human hematopoietic cells and is expressed more intensely on thymocytes than on mature peripheral blood $\mathrm{T}$ cells. A clear distinction was found by three-color flow cytometry between antigen density on single positive mature thymocytes subsets compared with the corresponding subset from peripheral blood. The 8D6 antibody did not have direct effects on T-cell activation or apoptosis, and the function of CDI47 in development and activation of T cells is not yet clear. Nevertheless, its highly regulated expression during T-cell differentiation and the structural characteristics of this antigen suggest that it has an interesting and important role in T-cell biology.
\end{abstract}

\author{
A. H. Kirsch, L. A. Diaz, Jr., \\ B. Bonish, P. A. Antony and D. A. Fox \\ ${ }^{1}$ Division of Rheumatology, Multipurpose \\ Arthritis and Musculoskeletal Diseases Center, \\ and Specialized Center of Research in \\ Rheumatoid Arthritis, University of Michigan, \\ Ann Arbor, USA
}

Key words: neurothelin - thymocyte - T cell

Received 11 February, revised, accepted for publication 3 March 1997
Cells of lymphoid origin and the central nervous system share a variety of surface markers, such as CD6, CD90 (Thy-1) and various adhesion molecules. Neurothelin, a glycoprotein which is expressed on endothelial cells, is thought to play an important role in the blood brain barrier (1). Other names for this molecule include HT7 (chick and mouse), OX-47 (rat), basigin (mouse), M6 (human) and EMMPRIN (1-4).

Neurothelin-related determinants are also expressed on cells of lymphoid origin. The OX-47 antigen is found at low levels on rat lymphocytes and is upregulated upon activation in both $\mathrm{T}$ and $B$ cells (2). The M6 antigen, present on peripheral granulocytes of patients with rheumatoid and reactive arthritis, is also expressed on a variety of Tcell, B-cell, erythroid, and myeloid cell lines (3). This structure has recently been designated CD147 by the 6th International Workshop and Conference on Human Leukocyte Differentiation Antigens (4). However, information is not yet available on the developmental expression of neurothelin by human lymphoid cells.

This article describes the pattern of expression of human CD147/neurothelin as recognized by a new monoclonal antibody termed 8D6. CD147/ neurothelin is widely expressed on cells of hematopoietic origin and has a specific pattern of expression during the development of $\mathrm{T}$-lineage cells.

\section{Material and methods}

Antibodies

Production of the 8D6 monoclonal antibody. A subtractive immunization technique was used to develop monoclonal antibodies to less immunogenic antigens or epitopes on the thymocyte cell surface. A 6-week-old female BALB/c mouse was serially immunized ( 3 immunizations at 2 -week intervals) with Peer cells, a human T-cell leukemic line. Each immunization was followed by treatment with cyclophosphamide, as previously described (5). The same mouse was then immunized and boosted twice with cells from a second leukemic T-cell line, Molt 13. Hybridoma 8D6 (IgG1) was subcloned and propagated in ascites form in pristane-primed mice. 


\section{Kirsch et al.}

Other antibodies: 7F8 (anti-CD98) was produced using the method described above (5). Anti-CD3tricolor, anti-CD4-phycoerythrin (PE), anti-CD8$\mathrm{PE}$ were obtained from Caltag. Fluorescein isothionyanate-conjugated goat anti-mouse antibody was obtained from Coulter. OKT3 (anti-CD3) was produced from hybridoma cells obtained from ATCC, and UMCD2 (anti-CD2) was produced as previously described (6). Anti-AD2 (7) was a gift from B. Haynes and D. Patel of Duke University.

\section{Cells}

Human peripheral blood mononuclear cells were obtained from venous blood of healthy volunteers by centrifugation over Ficoll-Hypaque. Thymic tissue was obtained as excess surgical material from children who underwent corrective cardiac surgery. It was finely minced and pressed through a stainless steel mesh to prepare a single-cell suspension. Thymocytes and peripheral blood mononuclear cells were separated from red blood cells and debris by centrifugation over Ficoll-Hypaque and washed three times.

The human T-cell leukemic lines HSB-2, Jurkat, Peer, Hut-78 and Molt 13 were maintained in continuous cell culture in our laboratory.

\section{Immunoprecipitation}

Cells of the HSB-2 T cell line were metabolically labeled with [35]-S-methionine for $4.5 \mathrm{~h}$ and then lysed and precleared as previously described (5), immunoprecipitated by incubating the lysate first with $8 \mathrm{D} 6$ antibody, followed by addition of protein-G Sepharose beads. Immunoprecipitates were analyzed by SDS-PAGE under reducing and nonreducing conditions.

\section{Flow cytometry analysis}

Single-color flow cytometry. Monoclonal antibodies were used at saturating concentrations. Surface antigen expression was determined using indirect or direct immunofluorescence using an Epics 3 or Elite Cell Sorter (Coulter Electronics, Hialeah, FL, USA). Cell populations of interest were selected using forward and right angle light scatter gating.

Three-color flow cytometry. Thymocytes and peripheral blood mononuclear cells obtained on the same day were placed into tubes $\left(5.0 \times 10^{5}\right.$ cells per tube) in $50 \mu$ l of phosphate-buffered saline (PBS). Fifty $\mu 1$ of antibody (8D6, 7F8 or controls) was added to appropriate tubes and incubated for 30 min at $4^{\circ} \mathrm{C}$. After washing twice with $2 \mu \mathrm{l}$ of PBS,
$5 \mu \mathrm{l}$ of CD4-PE or CD8-PE and $50 \mu \mathrm{l}$ of CD3-TC (or appropriate controls) were added and incubated for $30 \mathrm{~min}$ at $4^{\circ} \mathrm{C}$. Cells were washed twice with $2 \mathrm{ml}$ of PBS and resuspended in fixative (formaldehyde $1 \%$ ). Cells were analyzed by a Coulter Elite cell sorter.

T-cell activation

Proliferation assays. Mononuclear cells and thymocytes $\left(1 \times 10^{5}\right.$ cells/well $)$ were cultured in triplicate in round-bottom 96-well plates in RPMI 1640 (Bio Whittaker) supplemented with 10\% FCS (Gibco), $2 \mathrm{mM}$ glutamine and penicillin (100 $\mathrm{U} / \mathrm{ml}) /$ streptomycin $(100 \mathrm{U} / \mathrm{ml})$ at a total volume of $0.2 \mathrm{ml} /$ well. Cells were stimulated with PHA, PMA, IL-2, anti-CD2, anti-CD3, and anti-CD98. At day 4 of culture, wells were pulsed overnight with tritiated thymidine $(0.8 \mu \mathrm{Ci} /$ well $)$ and harvested, and thymidine incorporation was measured.

Kinetics of 8D6 expression. Peripheral blood mononuclear cells were cultured in RPMI supplemented with $10 \%$ FCS, glutamine, and penicillin/ streptomycin at $1 \times 10^{6}$ cells $/ \mathrm{ml}$ alone or with various mitogens including PMA $(1 \mathrm{ng} / \mathrm{ml})$, PHA $(0.5$ $\mu \mathrm{g} / \mathrm{ml})$, ionomycin $(0.5 \mu \mathrm{g} / \mathrm{ml})$, or a combination of PMA and ionomycin for 4 days at $37^{\circ} \mathrm{C}$. On days 2 and 4, a subset of cells under each condition were stained with 8D6 and several other antibodies including OKT3, anti-Tac (anti-CD25/IL-2R), 7F8 (anti-CD98).

\section{Apoptosis experiments}

Peripheral blood mononuclear cells were stimulated with PHA and then maintained in IL-2-containing medium as described above. Every 3-4 days, a subset of the blasts were subcultured in medium alone, or supplemented with 8D6 antibody (1:500) (or other agents with potential effects on apoptosis) for $24 \mathrm{~h}$. Cells were fixed in 1\% formaldehyde for $15 \mathrm{~min}$ at $0-4^{\circ} \mathrm{C}$ and then rinsed in PBS. One million cells were resuspended in $50 \mu \mathrm{l}$ of cacodylate buffer [0.2 M potassium cacodylate, $25 \mathrm{mM}$ Tris- $\mathrm{HCl}$ (pH 6.6), $2.5 \mathrm{mM}$ cobalt chloride, $0.25 \mathrm{mg} / \mathrm{ml}$ bovine serum albumin, $100 \mu \mathrm{l} / \mathrm{ml}$ terminal deoxynucleotidyl transferase, $0.5 \mathrm{mM}$ biotin-16 dUTP] and incubated for $30 \mathrm{~min}$ at $37^{\circ} \mathrm{C}$. Cells were rinsed in PBS and resuspended in 100 $\mu$ l of saline-citrate buffer $[2.5 \mu \mathrm{g} / \mathrm{ml}$ fluoresceinated avidin, $0.1 \%$ Triton $\mathrm{X}-100,5 \%(\mathrm{w} / \mathrm{v})$ non-fat dry milk, $0.6 \mathrm{M} \mathrm{NaCl}$ and $0.06 \mathrm{M}$ sodium citrate] and incubated for $30 \mathrm{~min}$ at room temperature in the dark. Cells were rinsed in PBS containing $0.1 \%$ Triton X-100 and resuspended in $1 \mathrm{ml}$ of PI buffer 


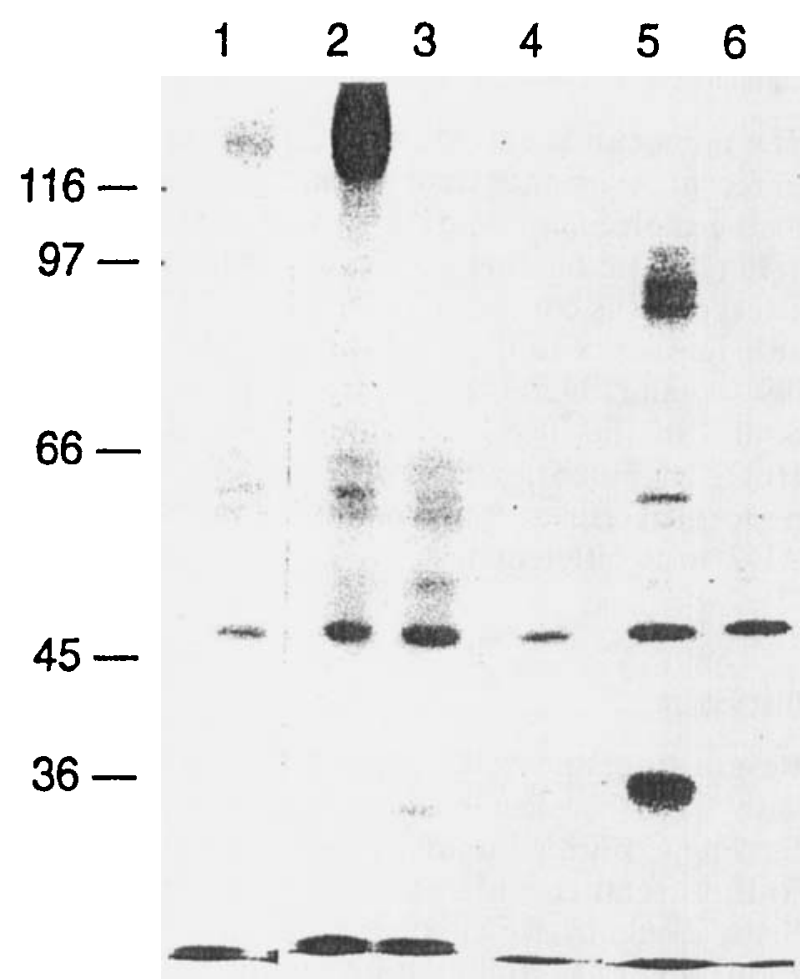

Figure 1. Structures recognized by the novel monoclonal antibody 8D6. Cells of the HSB-2 T cell line were metabolically labeled with [35]-S-methionine, lysed, precleared, immunoprecipitated, and analyzed by SDS-PAGE. Lanes 1-3, non-reduced; lanes $4-6$ reduced. Lanes 1 and 4 , control murine IgGl monoclonal antibody. Lanes 2 and 5, monoclonal antibody 7F8, which recognizes the CD98 heterodimer. Lanes 3 and 6 . monoclonal antibody $8 \mathrm{D} 6$, which recognizes a structure at $\sim 35$ $\mathrm{kDa}$ nonreduced and $\sim 40 \mathrm{kDa}$ reduced.

(PBS, $5 \mu \mathrm{g} / \mathrm{ml}$ PI, $0.1 \%$ RNAse A). Staining was analyzed by two-color flow cytometry.

\section{Results}

Characterization of structures recognized by the novel monoclonal antibody 8D6

The 8D6 antibody recognizes an antigen on HSB-2 cells of approximately $35 \mathrm{kDa}$ under non-reducing conditions and approximately $40 \mathrm{kDa}$ under reducing conditions, suggesting the presence of an intrachain disulfide bond (Figure 1). By comparing this biochemical data and the pattern of expression of the 8D6 antigen with known antigens from the Fifth International Leukocyte Workshop, the 8D6 antigen appeared to be a novel cell surface structure, not defined by CD classifications of the Fifth Workshop. Subsequently, in studies performed by the Sixth Workshop, 8D6 was found to identify CD147/neurothelin in binding assays both to transfectants and to beads coated with a CD147$\mathrm{Rg}$ fusion protein (4).
806 /neurothelin is expressed on a variety of cell types and is expressed more strongly on differentiated thymocytes than on mature $T$ cells

The 8D6 antibody binds to resting and activated peripheral blood mononuclear cells, thymocytes and transformed cell lines of both T-cell and nonT-cell origin. T-cell-derived populations that express 8D6 include Jurkat, HSB2, Peer, Molt 4 and Molt 13. Other cells that bind 8D6 include UMMel-1, a melanoma line, and HepG2, a hepatoma line. This antigen is also expressed on synovial $\mathrm{T}$ cells and synoviocytes.

Three-color flow cytometry analysis was performed to more precisely compare expression of CD147/neurothelin on thymocytes and peripheral blood $\mathrm{T}$ cells (Figure 2). The use of monoclonal antibodies to $\mathrm{CD} 3$ and $C D 4$ or CD3 and CD8 permitted selection of high $\mathrm{CD} 3\left(\mathrm{CD} 4^{+} \mathrm{CD} 8^{-}\right.$or $\mathrm{CD}^{-}{ }^{-} \mathrm{CD} 8^{+}$), mature thymocytes, with $\mathrm{CD} 3$ density comparable to peripheral blood $\mathrm{T}$ lymphocytes. This approach also permitted comparison of expression of 8D6/neurothelin on the CD4 and CD8 subsets. The results shown in Table 1 indicate that mature $\mathrm{CD}_{4}^{+}$and $\mathrm{CD} 8^{+}$thymocytes have a

\section{PBMC's}

CD3
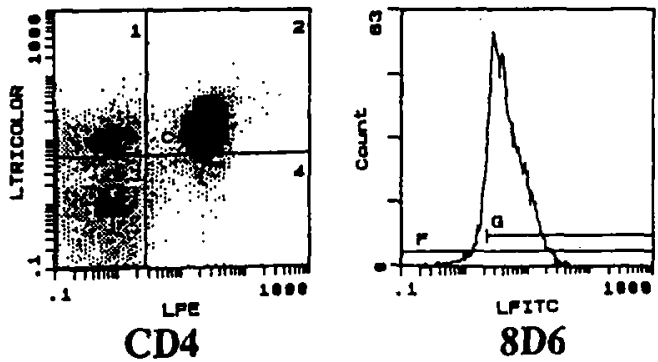

Thymocytes

CD3

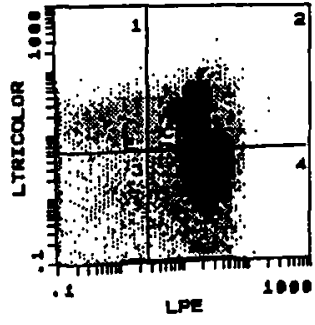

CD4

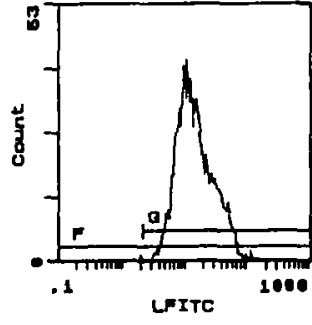

$8 D 6$
Figure 2. Three-color analysis of monoclonal antibody 8D6 reactivity with $\mathrm{CD}^{+}$thymocytes and $\mathrm{T}$ cells. Histograms of thymocytes and peripheral blood mononuclear cells stained directly with tricolor-conjugated anti-CD3 and phycoerythrinconjugated anti-CD4, and indirectly with monoclonal antibody 8D6. Left. Two-color histograms that identify the $\mathrm{CD}^{+} \mathrm{CD} 4^{+}$ subset in quadrant 2. The tricolor (CD3) background cursor is set to exclude low $\mathrm{CD}^{+}$(stage II) thymocytes. Right. Singlecolor histograms of 8D6 fluorescence gated on cells in quadrants 2 of adjacent panels. 


\section{Kirsch et al.}

Table 1

Relative binding of antibodies to thymocyte and peripheral blood T-cell subsets

\begin{tabular}{|c|c|c|c|}
\hline Antibody & Cell type & $\begin{array}{l}\text { Percentage } \\
\text { positive }\end{array}$ & $\begin{array}{l}\text { Net mean fluorescence } \\
\text { (background subtracted) }\end{array}$ \\
\hline 806 & CD3hi,CD4+ thymocyte & 99.4 & 15.515 \\
\hline 806 & $\mathrm{CD} 3^{+}, \mathrm{CD}^{+} \mathrm{PBMC}$ & 89.7 & 4.214 \\
\hline 806 & CD3hi,CD8 + thynocyte & 99.6 & 13.176 \\
\hline 806 & $\mathrm{CD}^{+}, \mathrm{CD}^{+} \mathrm{PBMC}^{-}$ & 95.1 & 4.46 \\
\hline CD98 & CD3hi,CD4 ${ }^{+}$thymocyte & 53.4 & 2.355 \\
\hline CD98 & $\mathrm{CD}^{+}, \mathrm{CD}^{+}{ }^{+} \mathrm{PBMC}$ & 16.4 & 0.884 \\
\hline C098 & CD3hi,CD8+ thymocyte & 63.0 & 2.816 \\
\hline $\operatorname{Cog} 8$ & $\mathrm{CD}^{+}, \mathrm{CO}^{+} \mathrm{PBMC}^{-}$ & 50.6 & 1.52 \\
\hline
\end{tabular}

Net mean fluorescence intensity (in arbitrary units) was calculated from single-color fluorescence histograms of CD147 (8D6) and CD98 staining, gated on thymocyte and peripheral blood T-cell subsets, as in Figure 2.

higher expression of both CD147/neurothelin antigen and the CD98 antigen (formerly termed the $4 \mathrm{~F} 2$ antigen) than peripheral blood $\mathrm{T}$ lymphocytes. This is most apparent when comparing the net mean fluorescence (Table 1). This suggests that the expression of this antigen is developmentally regulated, decreasing as thymocytes mature to become peripheral blood $\mathrm{T}$ cells.

\section{Expression of $8 \mathrm{D} 6 /$ neurothelin during short-term activation}

Peripheral blood mononuclear cells in short-term culture augment IL-2 receptor expression in the presence of various mitogens, including PHA, PMA ionomycin or a combination of ionomycin and PMA. In contrast, expression of 8D6/neurothelin decreases slightly by day 4 , as judged by net mean fluorescence (Figure 3). Similar results were obtained in the "blind panel" analysis conducted by the Sixth Leukocyte Differentiation Antigen Workshop (7). In studies using T-cell lines maintained in medium containing IL-2, expression of CDI47 was found to gradually increase after day 5 of culture, and high expression is found on longterm activated cells (data not shown).

\section{Functional assays}

The effects of 8D6 on thymocytes and peripheral blood mononuclear cells were examined by coculturing cells with PHA, PMA, IL-2, anti-CD2, antiCD3 and anti-CD28. No consistent inhibitory or costimulatory effects of the 8D6 antibody on T-cell or thymocyte proliferation under these conditions were found (data not shown). 8D6 did not appear to affect apoptosis in cultured thymocytes (data not shown).

\section{Comparison with $\mathrm{AD2}$}

The monoclonal antibody $\mathrm{AD} 2$ has been reported to recognize an antigen of similar molecular weight to the molecule immunoprecipitated by antibody 8D6 (7). The binding of 8D6 and AD2 to various cell types was compared. 8D6 and AD2 both bind at high density to the T-cell lymphoma line, Jurkat (99.7\% and $99.5 \%$, respectively). However, AD2 bound to the T-cell lymphoma lines HSB-2 and Hut78 at much lower density than 8D6. Studies performed during the Sixth Workshop clustered AD2 to a different novel antigen termed CD165 (7).

\section{Discussion}

Reactivity of the novel monoclonal antibody 8D6 with CD147/neurothelin has been established by binding to purified soluble protein, specific binding to transfectants, and dendrogram clustering in the Sixth Leukocyte Differentiation Antigen Workshop analysis. Immunoprecipitation of radiolabeled HSB-2 cells reveals a single band, which increases slightly in apparent molecular weight upon reduction, consistent with the intrachain disulfide bonds in the immunoglobulin-like regions of CD147. CD147/neurothelin is a highly glycosylated protein with a polypeptide core of $27.4 \mathrm{kDa}$. The apparent molecular weight of immunoprecipitated material from different cell sources varies, with sizes ranging from 35 to $60 \mathrm{kDa}$. It is likely that the antigen expressed on HSB-2 cells is somewhat less glycosylated than on other cell populations, given the relatively lower molecular weight and the relatively narrow band resolved by SDSPAGE. In contrast, immunoprecipitation of biotin labeled protein from Jurkat cells yielded a broad band in the range of $50-60 \mathrm{kDa}$ with a slight apparent shift to a higher molecular mass upon reduction (data not shown).

During the course of these studies, a monoclonal antibody termed AD2 was described with similar biochemical characteristics (8). However, cross-blocking studies and comparison of flow cytometric patterns on various cell lines indicated that AD2 did not recognize the same antigen as $8 \mathrm{D} 6$. Subsequently, the workshop analysis has clustered $\mathrm{AD} 2$ to a distinct novel $\mathrm{CD}$ designation, CD165 (7).

CD147/neurothelin, although described initially as a tumor cell antigen and as a component of the blood-brain barrier, is expressed widely on hematopoietic cells, with high expression on all cell lines examined. The data in this report demonstrate a particularly interesting pattern of expression on human T-lineage cells, with high-inten- 
Figure 3. Expression of 8D6/neurothelin during lymphocyte cultures, as analyzed by flow cytometry A. Net percentage of cells positive for 8D6 (upper 5 lines and symbols) or CD25/IL$2 \mathrm{R}$ (lower five lines and symbols). B. Mean channel fluorescence (MCF) for 8D6/neurothelin, expressed in arbitrary units.

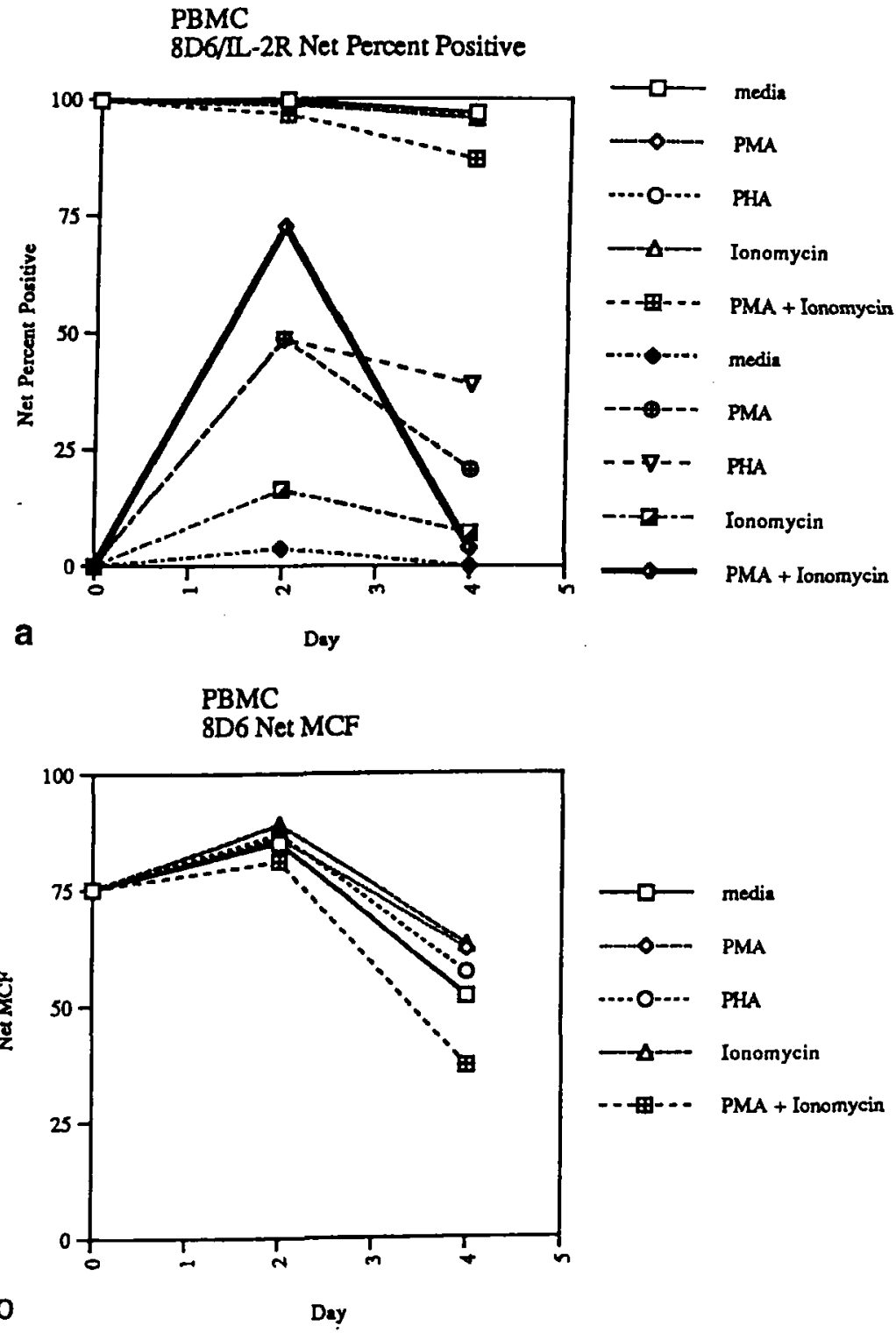

sity expression on thymocytes and somewhat lower levels of expression on mature peripheral blood $\mathrm{T}$ cells. When mature single-positive $\mathrm{CD}^{+}$or $\mathrm{CD} 8^{+}$ thymocytes were compared with the corresponding peripheral blood T-cell subset, three-fold or greater differences in antigen density were noted. A similar, although less striking, difference in antigen density was noted for CD98. Other T-cell differentiation antigens, such as CD3 and CD6, are expressed less strongly on thymocytes than on mature $T$ cells. It is not known yet whether cord blood $\mathrm{T}$ cells resemble thymocytes or resemble $\mathrm{T}$ lymphocytes from adult peripheral blood in terms of expression of CD147 and CD98. Although expression of CDI47 is strong on long-term activated $T$ cells and $T$-cell lines, it does not appear to be induced early in the course of T-cell activation in a manner comparable to the CD25 subunit of the IL-2 receptor or the CD98 antigen.
The regulated expression of CD147 during T-cell differentiation strongly suggests a function or functions for this molecule that may be specific to particular points in T-cell development. Studies thus far using the 8D6 monoclonal antibody have not yielded information as to the precise nature of the role of this structure in T-cell biology. Thus, 8D6 was neither mitogenic nor comitogenic for $T$ cells and failed to inhibit T-cell proliferative responses. Furthermore, it did not induce or prevent apoptosis of cultured human thymocytes. It has been speculated that CD147 may mediate adhesive function in certain cells, although no data to support this are yet available for lymphocytes. Designation of neurothelin to a new specific CD cluster and definition of a variety of monoclonal antibodies reactive with this molecule should now lead to progress in understanding its role during lymphocyte development and activation. 


\section{Kirsch et al.}

\section{References}

1. Seulberger $H$, Unger CM, Risau W. HT7, neurothelin, basigin, gp42 and OX-47 - many names for one developmentally regulated immuno-globulin-like surface glycoprotein on blood-brain barrier endothelium, epithelial tissue barriers and neurons. Neurosci Lett 1992: 140: 9397.

2. Fossum S, Mallett S, Barclay AN. The MRC OX-47 antigen is a member of the immunoglobulin superfamily with an unusual transmembrane sequence. Eur J Immunol 1991: 21: 671-679.

3. Kasinrerk W, Fiebiger E, Stefanova I, Baumruker T, Knapp $\mathrm{W}$, Stockinger $\mathrm{H}$. Human leukocyte activation antigen M6, a member of the Ig superfamily, is the species homologue of rat OX-47, mouse basigin, and chicken HT7 molecule. $J$ Immunol 1992: 149: 847-854.

4. Stockinger $H$, Ebel $T$, Hansmann $C$ et al. EC/18/776 neurothelin/basigin/M6/ EMMPRIN Workshop Panel Report. In: Kishimoto T, ed. Leukocyte typing VI. New York: Garland Press (in press).

5. Friedman AW, Diaz LA Jr, Moore S, Schaller J, Fox DA. The human 4F2 antigen: evidence for cryptic and noncryptic epitopes, and for a role of $4 F 2$ in human $T$ lymphocyte activation. Cell Immunol 1994: 154: 253-263.
6. Kozarsky KF, Tsai C, Bott CN Allada G. Li LL, Fox DA. An anti-CD2 monoclonal antibody that both inhibits and stimulates $T$ cell activation recognizes a subregion of $\mathrm{CD} 2$ distinct from known ligand-binding sites. Cell Immunol 1993: 150: 235-246.

7. Kishimoto T, ed. Leukocyte typing VI. New York: Garland Press (in press).

8. Bruggers CS, Patel DD, Scearce RM, Whichard LP, Haynes BF, Singer KH. AD2, a human molecule involved in the interaction of $T$ cells with epidermal keratinocytes and thymic epithelial cells. J Immunol 1995: 154: 2012-2022.

Address:

David A. Fox

Division of Rheumatology

University of Michigan

Room 3918

Taubman Center

P.O. Box 0358

Ann Arbor, MI 48109-0358

USA

Fax + 1 313-763-2025 